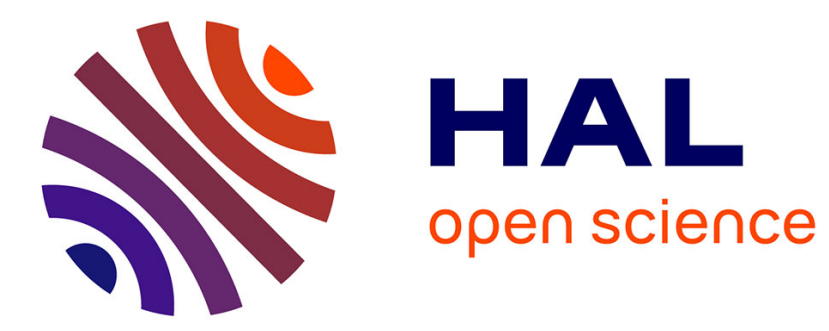

\title{
Reactive Functionalized Multilayer Polymers in a Coextrusion Process: Experimental and Theoretical Investigations of Interfacial Instabilities
}

\author{
Khalid Dr. Lamnawar, Abderrahim Maazouz, Patrice Laure
}

\section{To cite this version:}

Khalid Dr. Lamnawar, Abderrahim Maazouz, Patrice Laure. Reactive Functionalized Multilayer Polymers in a Coextrusion Process: Experimental and Theoretical Investigations of Interfacial Instabilities. 11th ESAFORM Conference on Material Forming, Apr 2008, Lyon, France. pp.Pages 763-766, 10.1007/s12289-008-0287-6 . hal-00510397

\section{HAL Id: hal-00510397}

https://hal-mines-paristech.archives-ouvertes.fr/hal-00510397

Submitted on 18 Aug 2010

HAL is a multi-disciplinary open access archive for the deposit and dissemination of scientific research documents, whether they are published or not. The documents may come from teaching and research institutions in France or abroad, or from public or private research centers.
L'archive ouverte pluridisciplinaire HAL, est destinée au dépôt et à la diffusion de documents scientifiques de niveau recherche, publiés ou non, émanant des établissements d'enseignement et de recherche français ou étrangers, des laboratoires publics ou privés. 


\title{
Reactive Functionalized Multilayer Polymers in a Coextrusion Process: Experimental and Theoretical Investigations of Interfacial Instabilities
}

\author{
K. Lamnawar ${ }^{1}$, A. Maazouz ${ }^{1(\Xi)}$ \\ ${ }^{1}$ Ingénierie des Matériaux Polymères-(IMP/LMM), UMR-CNRS 5223, INSA-Lyon, F-69621, 17 Avenue Jean \\ Capelle, Villeurbanne Cedex, France e-mail: Abderrahim.maazouz@insa-lyon.fr
}

P. Laure ${ }^{2}$

Centre de Mise Forme des Matériaux, Ecole Nationale Supérieure des Mines de Paris, UMR 7635 CNRS, 06904 Sophia Antipolis, France

ABSTRACT: Coextrusion technologies are commonly used to produce multilayered composite sheets or films for a large range of applications from food packaging to optics. The contrast of rheological properties between layers can lead to interfacial instabilities during flow. Important theoretical and experimental advances regarding the stability of compatible and incompatible polymers have, during the last decades, been made using a mechanical approach. However, few research efforts have been dedicated to the physicochemical affinity between the neighboring layers. The present study deals with the influence of this affinity on interfacial instabilities for functionalized incompatible polymers. Polyamide (PA6)/polyethylene grafted with glycidyl methacrylate (PE-GMA) was used as a reactive system and PE/PA6 as a non reactive one. Two grades of polyamide (PA6) were used in order to change the viscosity and elasticity ratios between PE (or PE-GMA) and PA6. It was experimentally confirmed, in this case, that weak disturbance can be predicted by considering an interphase of non-zero thickness (corresponding to an interdiffusion/reaction zone) instead of a purely geometrical interface between the two reactive layers. According to rheological investigations from previous work, an experimental strategy was here formulated to optimize the process by listing the parameters that controlled the stability of the reactive multilayer flows. Plastic films with two layers were coextruded in symmetrical and asymmetrical configurations in which PA6 was the middle layer. Indeed, for reactive multilayered systems, the interfacial flow instability could be reduced or eliminated, for instance, by (i) increasing the residence time or temperature in the coextrusion bloc (for $\mathrm{T}$ above the reaction temperature $\mathrm{T}=240^{\circ} \mathrm{C}$ ), and (ii) reducing the total extrusion flow rate. The reaction rate/compatibilization played a major role that must be taken into account. Furthermore, the role of the viscosity ratio, elasticity ratio, and layer ratio of the stability of the interface were also investigated coupling to the physicochemical affinity. The results show that it is necessary to obtain links between the classic factors that are introduced in the evaluation of the theoretical, given by linear stability analysis/longwave asymptotic investigations, and its corresponding experimental stability charts. Hence, based on this analysis, guide-lines for a stable coextrusion of reactive functionalized polymers can be provided.

Key words: Coextrusion- Interfacial instabilities- Rheology - Interdiffusion/reaction-- Interphase - Multilayer

\section{INTRODUCTION}

Coextrusion is an industrial process used to form multilayered sheets or films that are suitable for various products ranging from food packaging materials to reflective polarizers. The main problem is to simultaneously process polymers of different rheological properties. It is well known that under certain operating conditions, wavy interfaces can be observed inside the die, and this interfacial instability affects the quality of the final product. Important theoretical and experimental advances with regard to the stability of compatible and incompatible polymers have, during the last decades, been achieved using a mechanical approach [El Kissi et al. [1]].
Yih [2] first studied the stability of Poiseuille flows of two Newtonian fluids submitted to very long waves. By using a linear stability theory, he was able to demonstrate that a difference in viscosity could lead to instabilities, even for materials with low Reynolds numbers. His analysis was extended by numerous authors to other shearing flows. Although the subject is old in principle, we shall quickly list some investigations of close relevance to the present paper, for instance, the asymptotic methods developed by Hooper [3], Hooper and Boyd [4] or Yiantsios and Higgins [5]. Numerical solutions have been proposed by Anturkar et al. [6-7], and a global overview of theoretical results is given by Joseph and Renardy [8]. Several authors have carried out stability experiments mainly on polymeric liquids, 
including Han [9], Khan and Han [10], Karagiannis [11], and White et al. [12]. All these investigations have shown that the interfacial stability of multilayer flows can be determined by a number of factors including thickness, viscosity, density, elasticity ratios and interfacial tensions. The studies also demonstrated that the interfacial stability of multilayer flows was determined by a number of factors that were either essential (e.g., thickness, viscosity and elasticity ratios) or rather uninfluential (e.g., density ratios and interfacial tensions). Very comprehensive experiments have been carried out by Wilson and Khomami on both miscible and immiscible fluids [13-14]. Their facilities introducie temporally regular disturbances with controllable amplitudes and frequencies. The authors first investigated flows of immiscible fluids, and found that theoretically predicted growth rates agreed with their experimental data. Subsequently, they considered a plane Poiseuille flow of a compatible polymer system. In such a system, there is no interfacial tension and polymer chains are able to diffuse across the original interface, forming a diffuse interface (i.e. an interphase). In this case, growth rates were found to be much lower than those obtained for incompatible systems or for classic theoretical studies.

Valette et al. $[15,16]$ have investigated the interface stability (convective nature of interfacial instability) of a coextruded PE/PS flow. The experiments were performed under both industrial and laboratory conditions in order to point out the general behavior of such stable/unstable transitions. The transitions were observed by increasing the polyethylene flow rates or by decreasing the temperature.

Despite the interesting nature of this kind of research, it is of no help in understanding either the generation of instabilities or its connection with the physicochemical affinity and the resulting final properties of multilayer polymers. To the best of our knowledge, little work has, with regard to fundamental and experimental aspects, been dedicated to the physicochemical affinity between the neighboring layers and the interdiffusion/reaction present at the polymer/polymer interface.

In a previous study [17], we demonstrated that rheology coupled to morphological investigations could be a useful tool for (i) monitoring the competition between interdiffusion and reaction at polymer/polymer interfaces in bilayer sandwich structures and (ii) for modeling the interphase triggered between the neighboring layers [18].

The purpose of this communication, in accordance with these previous works, is to present theoretical and experimental studies dealing with the quantification of the influence of the physicochemical affinity/interphase on interfacial instabilities for functionalized incompatible polymers. The parameters that control the stability of the reactive multilayer flows are investigated and their relative importance is demonstrated in order to elaborate theoretical/experimental charts for a plane die in symmetrical and asymmetrical configurations.

\section{EXPERIMENTAL SECTION AND MAIN RESULTS}

\subsection{Base materials and methods}

Table 1 presents the main characteristics of the materials used in this study.

Table 1. The characteristics of the used materials.

\begin{tabular}{ll}
\hline Sample code & Trademark/Supplier/ Reactive groups \\
\hline PE & Lacqtene/ARKEMA/ Non-reactive \\
PE-GMA & LotaderAX8840/ARKEMA/ Epoxy Glycidyl \\
& functions \\
PA6 & 1) PA6 (1): Capron/BASF \& \\
& 2) PA6 (2): Ultramid/BASF/ \\
& Primary amino and carboxylic chain-ends
\end{tabular}

Polyamide (PA6)/polyethylene-grafted with glycidyl methacrylate (PE-GMA) was used as the reactive system and PE/PA6 as the non-reactive one. Two grades of polyamide (i.e., PA6 (1) and PA6 (2)) were employed in order to be able to vary the viscosity and elasticity ratios between PE (or PEGMA) and PA6. For the sake of clarity, the rheological properties (in both dynamic and capillary modes) of these materials are reported in detail elsewhere $[17 a, b ; 21]$. Relaxation times and viscosities of the present materials were fitted nicely by the White-Metzner models (which will be used in the theoretical approach to investigate the interfacial instabilities).

\subsection{Coextrusion process}

Multilayer were produced on a laboratory coextrusion line in the form of $360 \mathrm{~mm}$ wide films. Initially, the polymers were brought together in a feed block that distributed them into multiple alternating layers. Further details concerning this specific setup are described elsewhere [21].

An experimental strategy was organized to optimize the coextrusion process consisting in listing the various parameters governing the flow stability of reactive multilayer systems. Bilayer films were prepared, and configurations were obtained for the coextrusion of three to five layers. All configurations (bi-, tri- and five-layers) were realized at $240{ }^{\circ} \mathrm{C}$ and $260^{\circ} \mathrm{C}$, in order to be 
positioned at the interfacial reaction zone and allowing as to control the secondary reactions that can occur at high temperature (above $260^{\circ} \mathrm{C}$ ) during the coextrusion of reactive systems $[17,18,21]$.

\subsection{Experimental stability charts of reactive and non-reactive multilayer systems}

Figure 1 summarizes the experimental results obtained for the various bilayer systems where the empty and small hachured rectangles indicate the stability and instability zones, respectively: bilayer films of PA6(1)/PE and PA6(1)/PE-GMA were compared. Under these conditions, the resulting films were consistently unstable independntly of the process parameters (viscosity ratio (variable by changing the temperature), die gap, contact time in the feed block/die, etc.).

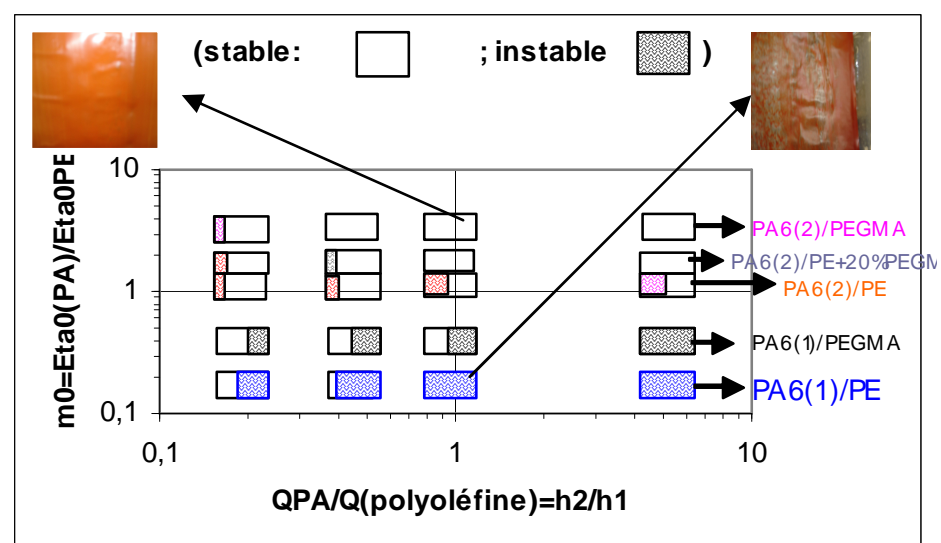

Fig. 1. A comparison of the stability/instability observed experimentally at $240^{\circ} \mathrm{C}$ with various viscosity and layer thickness ratios (evolution of the PA/Polyolefin viscosity ratio $\left(\mathrm{m}_{0}\right)$ vs their corresponding thickness ratio) for several bilayer systems : PA6(1)/PE; PA6(1)/PE-GMA; PA6(2)/PE;

PA6(2)/PEGMA, PA6(2)/PE+20\% PE-GMA.

PA6 (1)/(PE or PE-GMA) bilayer systems: In this case where the viscosity ratio is lower than 1 , a greater thickness was observed at the edge of the bilayer films thus demonstrating the contribution of the fluidity of PA6(1) in the encapsulation phenomenon. Moreover, a thinner PA6(1) layer was found to lower the rate of instabilities, especially in the case of PE-GMA/PA6(1). The principle of the thin layer was therefore valid in the present case which the use of thin layer of the less viscous material us PA6 (1) can improve the final quality of films. Nevertheless, these films remained unstable presenting somewhat chaotic interfacial defects.

PA6 (2)/PE or PE-GMA bilayer: In this case, PA6 (2)/PE structure, which the viscosity ratio $\left(\mathrm{m}_{0}=1\right)$, is more stable especially for slow PA6 (2) flow rate (i.e. $\left.h_{\mathrm{PA}} / \mathrm{h}_{\mathrm{PE}} \leq 1\right)$. Indeed, $\mathrm{PE}$ is more elastic than PA (2) and the use of thin layer of PA was found to lower the rate of elastic instabilities. Moreover, the PE-GMA/PA6 (2) structure presented a much higher stability at the temperature of $240^{\circ} \mathrm{C}$ compared to the PE/PA6 (2) bilayer system. Such measurements were performed on two stable PE-GMA/PA6 (2) bilayer systems that had been prepared with a contact time of $\sim 150 \mathrm{~s}$. Independently of the flow rate ratio, this configuration was found to be very stable: the longer the contact time in the feed block/die $(>150 \mathrm{~s})$, the better was the resulting stability. The interfacial chemical reaction that occurs after very short contact times, as in the case of coextrusion, could be evidenced by spectroscopic measurements. Despite the short contact time during the process, the compatibilization reaction took place at high temperature and under a high shear rate. Depending on the chosen processing parameters, this phenomenon required numerous investigations.

PA6 (2)/PE+ $x \%$ PE-GMA: bilayer blends of PE containing $5 \%$ and $20 \%$ of PE-GMA were coextruded with PA6(2) in order to probe the influence of the amount of PE-GMA on the stability of the flow. Thus, the final behavior of these systems was found to be somewhat intermediate between that of a non-reactive bilayer system (PE/PA) and that of a reactive system PE-GMA/PA6 (2). As a result, a larger amount of compatibilizer induced an enhanced quality of the film. In the future, it would be interesting to optimize the cost of using PE-GMA as a binding layer of multilayered systems.

Consequently, the interfacial instabilities that arise in the case of non reactive systems are reduced by the creation of a copolymer at the interface. In the case of the PE/PA6 structures, the copolymer that is created at the interface could be formed by adding a given percentage of PE-GMA to the PE matrix. The PE-GMA would thus react with the $\mathrm{NH} 2 / \mathrm{COOH}$ groups at the end of the PA6 chains [17a, 17b]. The contact time of various layers thus determines the time available for the reactions leading to the formation of the copolymers involved in the creation of the interphase. This phenomenon was a key parameter for the creation of the interphase, since it was found to depend strongly on parameters such as time and temperature. It could thereby be assumed that the increase in contact time through the decrease in the flow rate would allow us to optimize the creation of the interphase between the various layers $(\leftrightarrow 40 \mathrm{~nm})[17 \mathrm{~b}]$. Thus, a temperature of $240^{\circ} \mathrm{C}$ associated with a contact time longer than 2 min would be enough to provide a higher stability in the reactive multilayer. However, the tendency observed 
experimentally concerning the influence of the physico-chemical affinity at the polymer/polymer interface on the stability of this system was limited at higher temperatures (above $260^{\circ} \mathrm{C}$ ). The crosslinking reaction of the PE-GMA drastically altered the stability. These crosslinking reactions resulted in a higher elasticity in the PE-GMA layer, which could give rise to a much more pronounced difference between the rheological properties of the phases.

2.4. Longwave asymptotic investigations: First confrontations with experiments.

In this section, and according to the work of Valette et al. $[15,16]$, we have investigated the interfacial stability of a reactive and non-reactive system and tested the capability of theory to forecast the onset of wavy interface defects in comparison with experiment. Figure 2 shows an example of the stability curve obtained by the White-Metzner law at $240^{\circ} \mathrm{C}$ for PE-GMA/PA6 (2). It can be noticed that the theory predicted a much more significant zone of stability for the PE-GMA/PA6 (2) system according to experiment. Nevertheless, it was experimentally found that the stable films (Q PA/QPE-GMA=5 for example) were also situated in the unstable zones of the theoretical curve.

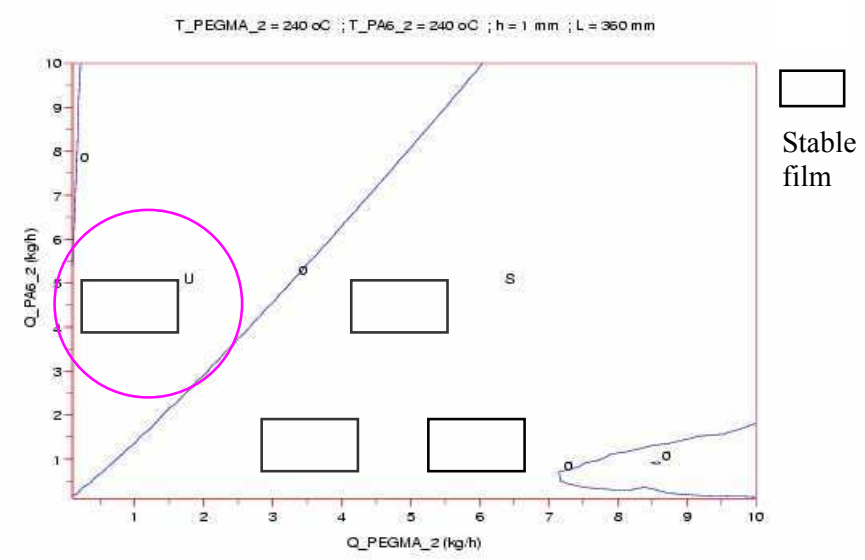

Fig.2. A comparison of the stability charts from the asymptotic study at $240^{\circ} \mathrm{C}$ with the experimental results of a PA6 (2)/PEGMA bilayer flow.

Consequently, it is necessary to obtain links between the classic factors that are introduced in the evaluation of the theoretical (given by linear stability analysis/longwave asymptotic investigations) and experimental stability charts taking into account the physicochemical affinity and the interphase triggered at the polymer/polymer interface.

\section{ACKNOWLEDGEMENTS}

We express our appreciation to professors J.F. Agassant, for its constructive and meticulous assessment of this work. MB thanks ARKEMA and BASF for providing the samples.

\section{REFERENCES}

1. El Kissi N., Piau J-M., Chaigneau R., Rhéologie 4, 1-17 (2003).

2 Yih, C.S., J. Fluid Mech., 27 (2), 337-352 (1967).

3 Hooper A.P., Phys. Fluids, 28, 1613-1619 (1985).

4 Hooper, A.P., Boyd, W.G.C., J. Fluid Mech., 128, 507-528 (1983).

5 Yiantsios, S.G., Higgins, B.G., Phys. Fluids, 31 (11), $3225-$ 3238 (1988).

6 Anturkar, N.R., Papanastasiou, T.C., Wilkes, J.O., AIChE Journal, 35 (5), 710-724-(1990).

7 Anturkar, N.R., Papanastasiou, T.C., Wilkes, J.O., Phys. Fluids A, 2 (4), 530-541 (1990).

8 Joseph, D.D., Renardy, Y.Y., Fundamentals of Two-Fluid Dynamics, Part I: Mathematical Theory and Applications, Springer- Verlag, New-York, (1992).

9 Han, C.D., J. Appl. Polym. Sci., 17, 1289-1303 (1973).

10 Khan, A.A., Han, C.D., Trans. Soc. Rheol., 20 (4), 595621(1976).

11 Karagiannis, A., Mavridis, H., Hrymak, A.N., Vlachopoulos, J., Polym. Eng. Sci., 28 (15), 982-988, (1988).

12 White, J.L., Ufford, R.C., Dharod, K.R., Price, R.L., J. Appl. Poly. Sci., 16, 1313-1330 (1972).

13 Wilson, G.M., Khomami, B., J. of Non-Newt. Fluid Mech., 45, 355- 384 (1992).

14 Wilson, G.M., Khomami, B., J. Rheol., 37 (2), 315-339(1993a).

15 Valette, R., Laure, P., Demay, Y., Agassant, J.-F., J. NonNewt. Fluid Mech., 121, 41-53 (2004).

16 Valette, R., Laure, P., Demay, Y., Agassant, J.-F., Int. Polym. Process., XVIII-2, 171-178 (2003).

17 (a) Khalid Lamnawar, Maazouz A, Rheol. Acta, (45), 411424 (2006). (b) Khalid Lamnawar, Maazouz A, Rheol. Acta, paper 244 (In press 2007).

18. Bousmina M, Palierne J.F, Utracki L.A, Polym. Engin. \& Science 39, 1049-1059 (1999).

19 Koriyama H, Oyama HT, Ougizawa T, Inoue T, Weber M, Koch E. Polymer 40, 6381(1999).

20 Patlazhan S., Schlatter G., Serra C., Bouquey M., Muller R, Polymer 47, 6099-6106 (2006).

21. (a) Khalid Lamnawar, A MAAZOUZ, AIP Conf. Proc. (907): 908914 (2007). (b) Khalid Lamnawar, PHD thesis, INSA-Lyon (2007) 